\title{
Optimization of Dissolved Fe(III) Determination in Coastal Water by Using Electrochemistry Approach and 2, 3- Dihydroxynaphthalene as the Binding Ligand
}

\author{
Nur Jannati Ramjam and Khairul Nizam Mohamed* \\ Environmental Science Department, Faculty of Forestry and Environment, Universiti Putra Malaysia, \\ 43400 Serdang, Selangor, Malaysia \\ *E-mail: ﹎.nizam@upm.edu.my
}

Received: 19 March 2021 / Accepted: 25 June 2021 / Published: 10 August 2021

\begin{abstract}
An optimization procedure was developed in this study using Competitive Ligand Exchange-Adsorptive Cathodic Stripping Voltammetry (CLE-AdCSV) to determine the concentration of dissolved Fe(III) in coastal water collected at Pulau Redang, Terengganu. The method was optimized for the UV-irradiation period for dissolved organic digestion, while the $\mathrm{pH}$ of the samples prior to UV-irradiation was determined. Additionally, the types and concentrations of the artificial ligands, followed by the sample equilibration period for sample measurements, were confirmed and performed. A small standard deviation of 0.002 was obtained in this experiment, indicating that the data obtained were precise when the optimized method was applied. Those optimized method was applied to the samples at Station 3, and the data obtained were compared with the previous study. Our present data showed that the concentration of dissolved Fe(III) was low, approximately 6 - 82 times lower than previously reported data. As our study area was affected by the Northeast monsoon (NEM), the phenomenon of strong turbulence during the post-monsoon event could have caused the resuspension of bottom sediment to the upper layer of seawater. Hence, the total suspended solids (TSS) level could have increased in the water column, suggesting that $\mathrm{Fe}$ (III) was mainly attached to the particulate phase rather than during the dissolved phase.
\end{abstract}

Keywords: dissolved iron, coastal water, voltammetry, speciation, organic ligands

\section{FULL TEXT}

(C) 2021 The Authors. Published by ESG (www.electrochemsci.org). This article is an open access article distributed under the terms and conditions of the Creative Commons Attribution license (http://creativecommons.org/licenses/by/4.0/). 